\title{
MICROCLIMA E PRODUÇÃO DA UVA DE MESA 'NIAGARA ROSADA' CONDUZIDA EM ESPALDEIRA A CÉU ABERTO E EM MANJEDOURA NA FORMA DE "Y" SOB COBERTURA DE TELADO PLÁSTICO'
}

\author{
MÁRIO JOSÉ PEDRO JÚNIOR ${ }^{2}$, JOSÉ LUIZ HERNANDES ${ }^{3}$, \\ GLAUCO DE SOUZA ROLIM ${ }^{4}$, GABRIEL CONSTANTINO BLAIN ${ }^{5}$
}

RESUMO - Foi desenvolvido um experimento em vinhedos de 'Niagara Rosada', conduzidos em espaldeira e em manjedoura na forma de Y com cobertura de telado plástico, visando a comparar as alterações microclimáticas induzidas pelo sistema de condução e uso de telado plástico, e o efeito na produtividade das videiras. Entre os parâmetros microclimáticos avaliados, apenas a radiação solar foi atenuada pelo telado plástico em cerca de $20 \%$, acima do dossel, tendo sido transmitido para a altura do cacho, cerca de $41 \%$ da radiação solar no sistema em Y sob telado plástico e $21 \%$ no espaldeira. As temperaturas máximas e mínimas foram semelhantes em ambos os sistemas. A produção por planta e a massa dos cachos foram mais elevadas no sistema em Y sob telado plástico, em comparação ao espaldeira.

Termos de indexação: uva de mesa, radiação solar, sistema de condução, cultivo protegido.

\section{MICROCLIMATE AND YIELD OF 'NIAGARA ROSADA' GRAPEVINE GROWN IN VERTICAL UPRIGHT TRELLIS AND "Y" SHAPED UNDER PERMEABLE PLASTIC COVER OVERHEAD.}

\begin{abstract}
A field trial was conducted in vineyards of 'Niagara Rosada' grapevine conducted in the following trellis systems: vertical upright trellis with single cordon and the Y-shaped with plastic overhead cover in order to compare microclimatic changes in the vineyard due to the trellis system and the use plastic cover and the yield of the grapevines. It was observed that the maximum and minimum temperatures were similar in both systems evaluated. Solar radiation was attenuated by about $20 \%$ by the plastic overhead cover and $41 \%$ of outside solar radiation was transmitted to the cluster height in the Y-shaped system and $21 \%$ for the vertical upright trellis. The yield and cluster weight were higher in the Y-system with plastic overhead cover when compared to the vertical trellis system
\end{abstract}

Index terms: table grape, solar radiation, trellis system, protected cultivation.

\section{INTRODUÇÃO}

A atividade vitícola da região produtora compreendida pelos municípios de Jundiaí e Louveira, no Estado de São Paulo, está baseada na cultivar de uva de mesa 'Niagara Rosada', cujo principal sistema de condução das videiras utilizado pelos produtores é a espaldeira com cordão esporonado único e a céu aberto.

Recentemente, foi divulgada em Santa Catarina a utilização do sistema de sustentação das videiras em manjedoura, na forma de 'Ypsilon' (EPAGRI,
2006), que tem sido utilizado em diferentes áreas vitícolas do País. O arranjo estrutural do sistema em formato de $\mathrm{Y}$ aberto facilita a utilização de materiais de cobertura, permitindo o cultivo da videira em ambiente protegido. Esses ambientes fechados ou semiabertos, apesar de maior custo de instalação, têm-se mostrado vantajosos ao viticultor por contribuir para aumentar a produção e a melhoria da qualidade dos cachos, propiciando melhor exposição à radiação solar (SCHUCK et al., 2004), além de oferecer proteção contra as perdas causadas por granizo (EPAGRI, 2006).

\footnotetext{
${ }^{1}$ Trabalho Sinfruit 087 - Simpósio Internacional de Fruticultura - Avanços na Fruticultura (17 a 21 Outubro)

Recebido para publicação em

${ }^{2}$ Eng. Agr. Dr., PqC Centro de Ecofisiologia e Biofísica, IAC, Campinas-SP, Brasil. E-mail: mpedro@iac.sp.gov.br Bolsista do CNPQ

${ }^{3}$ Biólogo MS., PqC Centro de Fruticultura, IAC, Jundiaí-SP, Brasil. E-mail: jlhernandes@iac.sp.gov.br

${ }^{4}$ Eng. Agr. Dr., PqC Centro de Ecofisiologia e Biofísica, IAC, Campinas-SP, Brasil. E-mail: glaucorolim@gmail.com

${ }^{5}$ Eng. Agrícola Dr., PqC Centro de Ecofisiologia e Biofísica, IAC, Campinas-SP, Brasil. E-mail: gabriel@iac.sp.gov.br
} 
O cultivo da videira em ambiente protegido tem sido intensificado nas diferentes regiões vitícolas do País, tanto para produção de uvas para vinho (FERREIRA et al., 2004; MOTA et al., 2008; DETONI et al., 2007; SILVA et al., 2008; CHAVARRIA et al., 2009) quanto para mesa (SCHIEDECK et al., 1999; LULU et al., 2005; CONCEIÇÃO;MARIN, 2010). Porém, deve-se ressaltar que a utilização do cultivo da videira em ambiente protegido pode promover modificações no microclima do vinhedo (FERREIRA et al., 2004; LULU, 2005; CHAVARRIA et al., 2009), principalmente em função das alterações na transmissão da radiação solar.

No caso da uva de mesa 'Niagara Rosada', o cultivo protegido com telado plástico foi utilizado por Peruzzo (1990), em Viçosa (MG), que verificou perda da massa do cacho. Na região de Bento Gonçalves (RS), Conte (1996) obteve baixos valores de rendimento médio na uva cultivada sob estufa plástica, porém relata que o produto teve boa qualidade. Mais tarde, Schiedeck et al. (1999) verificaram que videiras cultivadas em estufas de plástico mostraram precocidade de maturação em relação às conduzidas a céu aberto.

Em Caldas (MG), Ferreira et al. (2004) utilizaram poda antecipada, aliada ao uso de cobertura plástica, para antecipação do período de colheita da 'Niagara Rosada'. Mais recentemente, Gonçalves (2007), avaliando o efeito de sombreamento contínuo, verificou efeito depreciativo na produção devido ao excesso de absorção de radiação solar pelo telado plástico.

Os produtores da região noroeste do Estado de São Paulo têm utilizado com sucesso telados plásticos com malha de $18 \%$ para proteção contra ataque de pássaros, granizo e excesso de sol (TERRA et al., 1997; CONCEIÇÃO; MARIN, 2009). Atualmente, esse material para a proteção das videiras tem sido largamente usado na região produtora de Louveira, em virtude de proteção ao granizo e ataque de pássaros.

Em função das vantagens, para o cultivo da 'Niagara Rosada', relativas ao uso do sistema de condução em Y e do cultivo protegido, foi conduzido este experimento, visando a caracterizar este sistema de produção na região vitícola de Louveira (SP), durante o ciclo de verão, objetivando caracterizar as alterações microclimáticas nos vinhedos, e avaliar a influência na massa dos cachos e a produtividade das videiras cultivadas em ciclo de verão.

\section{MATERIAL E MÉTODOS}

O experimento foi realizado em vinhedos comerciais de 'Niagara Rosada', situados no município de Louveira (SP). De acordo com Köeppen, o clima da região é Cfa, definido como subtropical (mesotérmico). O ensaio foi conduzido durante o período da safra de verão, nos anos de 2008 e 2009, em vinhedos conduzidos em espaldeira, com cordão esporonado unilateral, a céu aberto e em manjedoura na forma de "Y" (EPAGRI, 2006), com cobertura de telado plástico (clarite com valor nominal de $18 \%$ de transmissão de radiação solar cobrindo as ruas de videiras). $\mathrm{O}$ espaçamento no vinhedo em manjedoura na forma de "Y" foi de 2,8x1,6 m, com ocupação espacial de 4,48 $\mathrm{m}^{2}$.planta ${ }^{-1}$, estimando-se em 2.232 plantas/hectare, enquanto o conduzido em espaldeira foi $1,5 \times 0,8 \mathrm{~m}$, ocupando $1,2 \mathrm{~m}^{2}$. planta $^{-1}$ ou 8.333 plantas.ha ${ }^{-1}$. O porta-enxerto utilizado foi o IAC-766, sendo efetuada poda curta de inverno nas plantas conduzidas em espaldeira e poda mista nas plantas conduzidas em "Y", com cobertura de telado plástico, durante a primeira quinzena de agosto de cada ano.

A caracterização do microclima dos vinhedos, nos diferentes sistemas de condução, foi feita durante o ano de 2008, por meio de estações meteorológicas automáticas da Davis, programadas para leituras a cada minuto e obtenção de valores diários de: temperatura do ar $\left({ }^{\circ} \mathrm{C}\right)$, umidade relativa do ar $(\%)$ e radiação solar $\left(\mathrm{MJ} \cdot \mathrm{m}^{-2} \cdot \mathrm{dia}^{-1}\right)$. Os sensores de temperatura e umidade relativa do ar foram instalados na altura dos cachos, enquanto os de radiação solar foram instalados acima do dossel e na altura dos cachos.

As avaliações dos parâmetros fitotécnicos foram realizadas em 30 plantas, na época da colheita, e constaram de: produção (kg/planta); massa dos cachos $(\mathrm{g})$; número de cachos; comprimento e largura dos cachos $(\mathrm{cm})$.

Os valores médios das variáveis microclimáticas e fitotécnicas obtidos para os diferentes sistemas de condução (Y sob telado plástico e espaldeira a céu aberto) foram comparados por análise de regressão e pelo teste $t$ para amostras com variância equivalente ao nível de $5 \%$ de probabilidade.

\section{RESULTADOS E DISCUSSÃO}

Os resultados obtidos objetivando comparar os sistemas de condução em espaldeira a céu aberto e em Y sob telado plástico são apresentados, considerando-se: a) alterações microclimáticas; b) produção; c) massa e tamanho dos cachos.

Alterações microclimáticas - Os valores de temperatura do ar, máxima (Figura 1a) e míni- 
ma (Figura 1b), foram semelhantes nos diferentes sistemas de condução durante o período analisado, uma vez que o valor do coeficiente angular da reta de comparação é próximo de um, e o coeficiente linear, praticamente zero. Conceição e Marin (2009) também não obtiveram alterações nos valores de temperatura máxima e mínima pelo uso de telado plástico em vinhedos. Essas pequenas diferenças nos valores das temperaturas extremas, em vinhedos conduzidos a céu aberto e sob telado plástico, são provavelmente devidas à uniformização das condições ambientais provocadas pelo vento em sistemas semiabertos (FERREIRA et al., 2004). No caso da temperatura máxima do ar, diferentes autores têm relatado maiores valores em vinhedos com cobertura de plástico em relação à condição a céu aberto (LULU;PEDRO JÚNIOR, 2006; CHAVARRIA et al., 2007; CARDOSO et al., 2008; CHAVARRIA et al., 2009).

Também não foi notada diferença na comparação dos valores médios diários de umidade relativa (Figura 1c) do ar nos sistemas em espaldeira e em Y sob telado plástico. Também, Conceição e Marin (2009) não notaram diferença ao comparar vinhedos com e sem cobertura de telado plástico. Outros autores também não observaram diferenças na umidade relativa do ar, mesmo quando os vinhedos eram cobertos por plástico impermeável (LULU; PEDRO JÚNIOR, 2006; CHAVARRIA et al. 2007; CHAVARRIA, et al., 2009). Apenas, deve-se considerar que, no presente experimento, foi observado que valores de umidade relativa do ar inferiores a 90\% têm tendência a serem mais elevados no sistema de condução em Y sob telado plástico, em comparação ao espaldeira.

Na Figura 1 d, 1e, 1f são apresentadas as comparações entre os valores diários de radiação solar obtidos no ambiente externo, abaixo do telado plástico e acima do dossel das videiras em Y e na altura dos cachos das plantas em espaldeira e em Y sob telado plástico.

A comparação da radiação solar externa e a transmitida para a altura dos cachos das videiras permitiu verificar terem sido os valores de transmissão no sistema em espaldeira (Figura 1f) menos elevados que no sistema de condução em Y sob telado plástico (Figura 1e). Apesar do efeito do telado plástico (Figura 1d), houve maior transmissão de radiação solar no sistema em Y, comparado ao espaldeira, propiciado pela disposição oblíqua dos ramos, formando apenas uma camada de folhas atuando na redução de radiação solar ao nível dos cachos. Por sua vez, o sistema em espaldeira com ramos dispostos na vertical permite a formação de várias camadas de folhas que influenciam na transmissão de radiação solar para o nível dos cachos.

Na Tabela 1, são apresentados os valores médios das variáveis microclimáticas obtidas nos vinhedos conduzidos em espaldeira a céu aberto e em Y sob telado plástico. Não foi observada diferença estatística entre os sistemas de condução para temperatura do ar máxima e mínima e umidade relativa do ar. As diferenças observadas nos vinhedos foram da ordem de $0,1^{\circ} \mathrm{C}$ para as temperaturas e de $1,9 \%$ para umidade relativa do ar. Essas pequenas diferenças entre as variáveis microclimáticas foram também observadas por Gonçalves (2007) em vinhedos de 'Niagara Rosada' conduzidos sob telado plástico com $30 \%$ de sombreamento. Como os telados são utilizados apenas como cobertura, sem fechamento lateral, permitem a livre passagem dos ventos, uniformizando as condições ambientes (temperatura e umidade relativa do ar).

Conceição e Marin (2009) obtiveram, no interior de vinhedos conduzidos sob tela plástica, valores de umidade relativa superiores em $4 \%$ aos dos obtidos em posto meteorológico. Essa maior diferença foi devida ao uso de irrigação no vinhed,o propiciando um ambiente mais úmido que o exterior. As maiores diferenças entre os sistemas de condução foram observadas na radiação solar global. Os valores médios obtidos em condição de céu aberto foram de 16,3 MJ.m ${ }^{-2} \cdot$ dia $^{-1}$ (Tabela 1), variando entre os extremos 1,5 e 23,6 MJ.m ${ }^{-2}$.dia ${ }^{-1}$ (Figura 1), durante o período analisado. Para as medições efetuadas abaixo do telado plástico e acima do dossel do vinhedo conduzido em Y, foram obtidos valores entre 1,2 e $18,6 \mathrm{MJ} \cdot \mathrm{m}^{-2} \cdot \mathrm{dia}^{-1}$ com uma transmissão média de radiação solar de 79,6\% (Tabela 1). Esse valor de transmissão de radiação solar é função da característica do material usado como cobertura das plantas e foi semelhante ao relatado por Conceição e Marin (2009), que verificaram em vinhedo coberto com tela plástica de polietileno, com sombreamento nominal de $18 \%$, redução da radiação solar incidente de $20 \%$.

A transmissão da radiação solar na altura dos cachos do tratamento ' $\mathrm{Y}$ ' com telado plástico foi de 41,4\% (Tabela 1). Esse valor foi obtido em função da transmissão de radiação solar de 20,4 pelo telado plástico e cerca de $40 \%$ pelo dossel do vinhedo, cuja disposição dos ramos e folhas é levemente inclinada em relação à horizontal. No caso do sistema em espaldeira, a transmissão de radiação solar ao nível dos cachos foi de 20,6\%. Esse valor foi semelhante aos obtidos por Pedro Júnior et al. (2006), que relataram uma variação entre 14 e $23 \%$ para o período de maior enfolhamento das plantas. A maior absorção 
de radiação solar no sistema em espaldeira é devida à distribuição na vertical das folhas dos ramos.

Em função das pequenas alterações microclimáticas encontradas para valores médios diários da temperatura do ar e umidade relativa, são apresentadas na Figura 2 a variação diária da radiação solar, temperatura do ar e umidade relativa durante dias característicos: nublado (Figura 2 a,b,c) e ensolarado (Figura $2 \mathrm{~d}, \mathrm{e}, \mathrm{f}$ ), visando a comparar as diferenças microclimáticas dos sistemas de condução da videira em Y sob telado plástico e em espaldeira.

Em dia considerado nublado, a radiação solar externa atingiu valores de $250 \mathrm{~W} . \mathrm{m}^{-2}$, enquanto ao nível dos cachos do vinhedo em espaldeira foi observado cerca de 40 a $50 \mathrm{~W} \cdot \mathrm{m}^{-2} \mathrm{e}$ no Y sob plástico cerca de $180 \mathrm{~W} . \mathrm{m}^{-2}$. Por outro lado, em dia considerado ensolarado, com radiação solar no ambiente externo de 900 W. $\mathrm{m}^{-2}$, no Y sob telado plástico, observou-se $600 \mathrm{~W} \cdot \mathrm{m}^{-2}$ e no espaldeira $200 \mathrm{~W} \cdot \mathrm{m}^{-2}$ na altura dos cachos (Figura 2).

A umidade relativa no dia nublado (Figura $2 b$ ) foi superior no sistema em espaldeira quando comparado ao Y sob telado plástico, durante todo o dia, em cerca de $10 \%$. Provavelmente, no sistema em Y, com os cachos mais elevados do nível do solo $(1,5 \mathrm{~m})$ permitiram maior aeração em relação ao espaldeira (0,9 a $1 \mathrm{~m}$ acima do solo). Em dia ensolarado (Figura 2e), a umidade relativa no sistema em espaldeira foi superior ao Y com telado das 12 às 20 horas, propiciado, provavelmente, pela menor incidência de radiação solar nesta região da espaldeira. Nas outras horas do dia, foram semelhantes.

No caso da temperatura do ar, foram observados, em dia nublado (Figura $2 \mathrm{c}$ ), valores semelhantes durante todo o dia, nos diferentes sistemas de condução avaliados. Apenas em dia ensolarado (Figura 2f) os valores da temperatura nos vinhedos em espaldeira, na altura dos cachos, foram superiores aos obtidos no Y sob telado plástico, das 8 às 18 horas, quando o sol estava exercendo influência sobre as plantas. Também a posição do sensor de temperatura em relação ao nível do solo, isto é, mais baixo no espaldeira, deve ter influenciado na obtenção de valores mais elevados em relação ao Y.
Produção e massa dos cachos. Na Tabela 2, são apresentados os valores médios de produção da 'Niagara Rosada' nos diferentes sistemas de condução. Para cada ano em separado, foi observada diferença estatística entre os valores obtidos, tendo apresentado o Y com telado plástico produções superiores ao sistema de condução em espaldeira em torno de $20 \%$, na média dos dois anos avaliados. No caso da produtividade, apesar dos espaçamentos diferentes dos sistemas de condução, observou-se ter sido o Y sob telado superior ao espaldeira, respectivamente, com valores médios de 31,46 e 26,23 t.ha ${ }^{-1}$. A alta produtividade apresentada pelo sistema em espaldeira, bem superior à média regional (12 a 18 t. ha $\left.{ }^{-1}\right)$, deve-se a algumas características específicas da área estudada. $\mathrm{O}$ experimento foi realizado em vinhedo comercial com plantio muito adensado (8333 planta.ha $\left.{ }^{-1}\right)$. Entretanto, observa-se que tal nível de produtividade não se tem mantido nos anos seguintes. Durante a safra de verão de 2009, verificou-se maior diferença nos valores de produtividade entre os sistemas de condução, evidenciando o melhor potencial produtivo do sistema em ' $\mathrm{Y}$ '. Pedro Júnior. et al. (2011) também obtiveram altas produções em Niagara Rosada conduzida em Y sob cultivo protegido.

Em relação à massa e tamanho dos cachos, foi verificado que, no sistema em Y sob telado plástico, os valores foram superiores aos da espaldeira, indicando que o produtor poderá conseguir melhores preços de venda pela melhor qualidade do produto. A massa dos cachos no sistema em Y sob telado plástico teve valores superiores ao espaldeira em cerca de $10 \%$, enquanto o tamanho (comprimento e largura) foi superior em cerca de $15 \%$.

$\mathrm{O}$ número de cachos no sistema em $\mathrm{Y}$ foi superior ao da espaldeira devido ao tamanho das plantas propiciado pelo maior espaçamento entre plantas no Y, em comparação ao espaldeira e também por ter sido utilizada poda curta na espaldeira, enquanto no $\mathrm{Y}$ foi feita poda mista, propiciando maior número de gemas e, consequentemente, maior número de ramos por planta. 

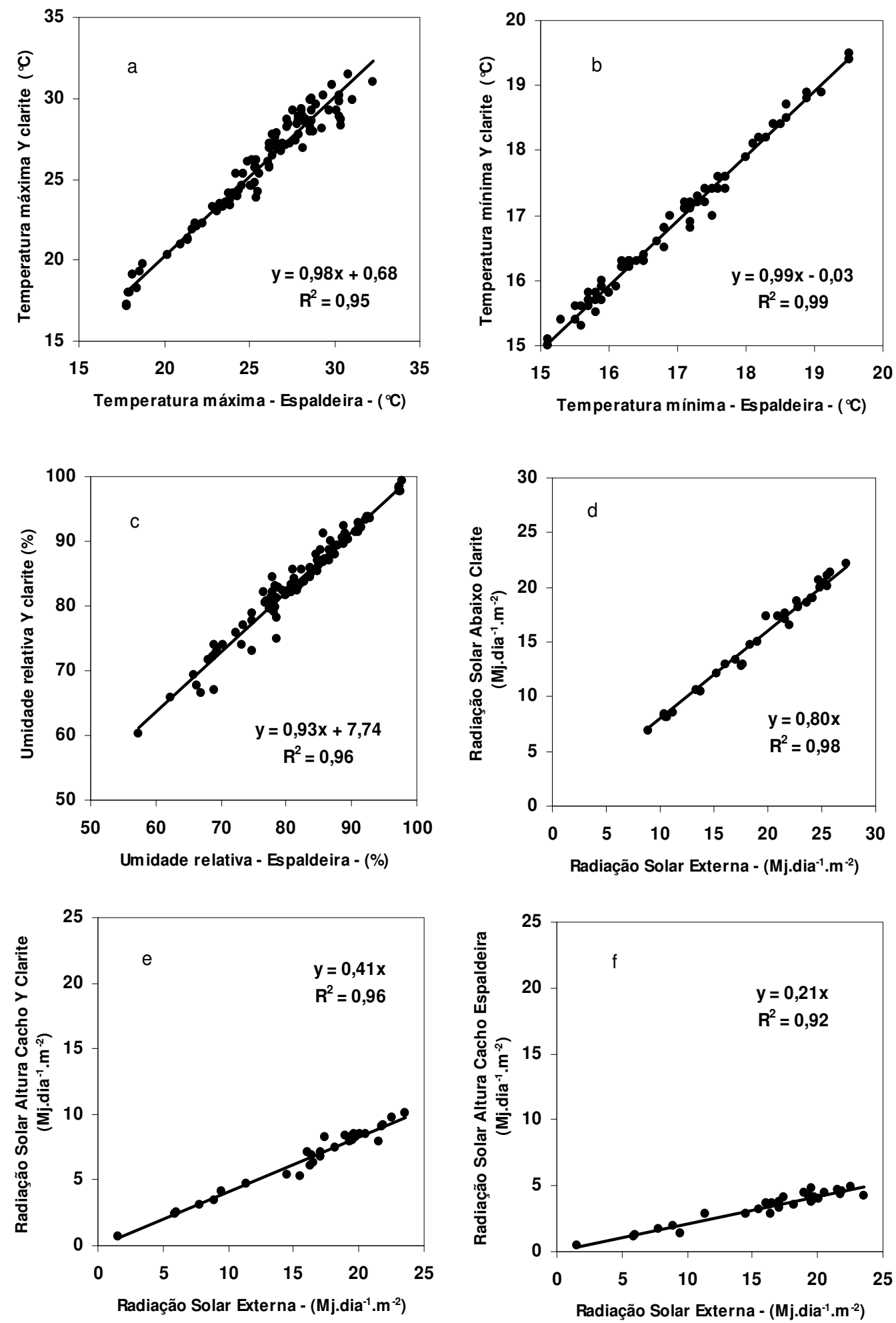

FIGURA 1 - Comparação entre valores diários de radiação solar, temperatura do ar mínima e máxima e umidade relativa do ar medidos na altura dos cachos da videira 'Niagara Rosada' conduzida em Y sob telado plástico e em espaldeira a céu aberto, em Louveira (SP). 

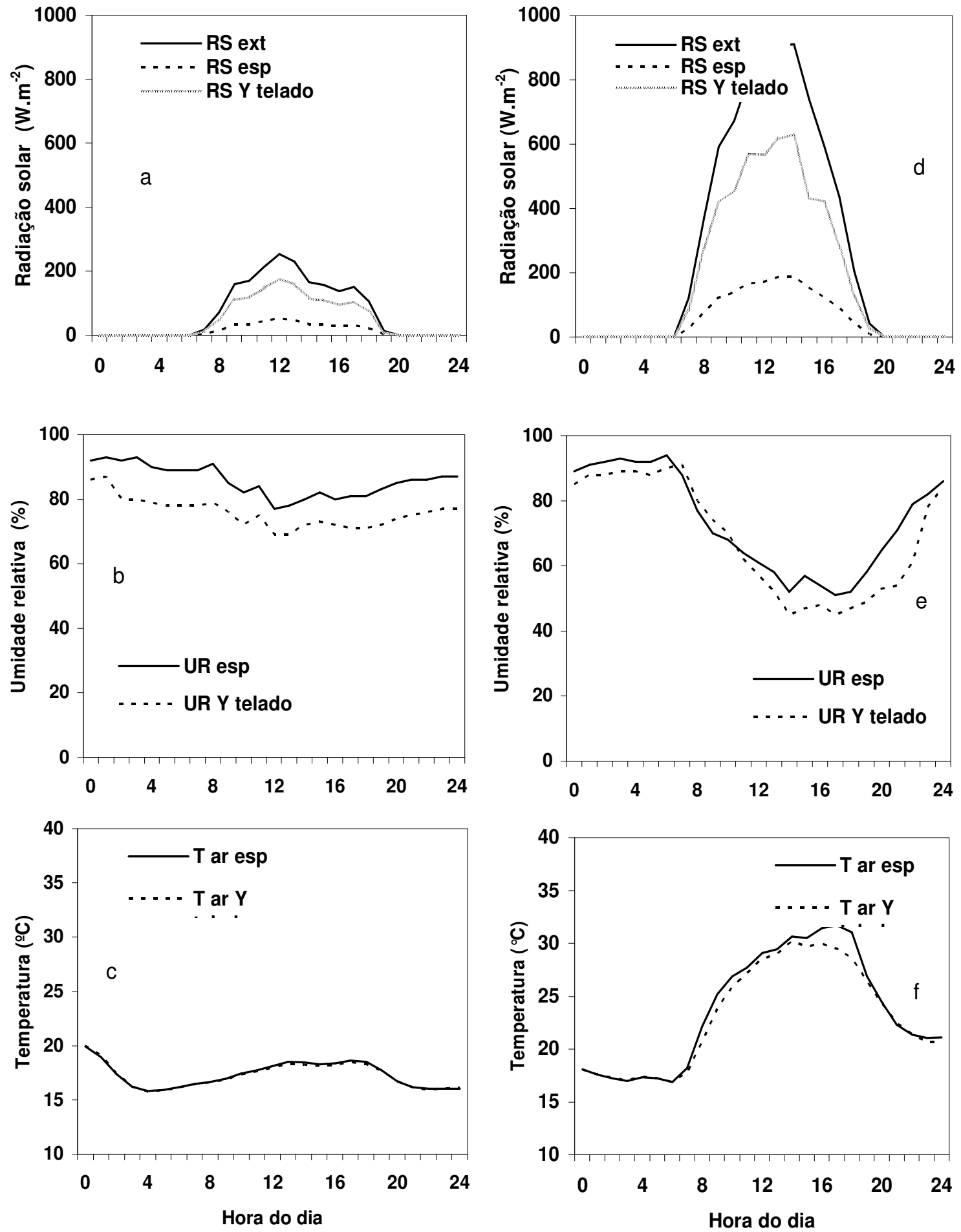

FIGURA 2 - Variação diária da radiação solar (RS); temperatura do ar (T ar) e umidade relativa (UR) medidas ao nível dos cachos em vinhedos de 'Niagara Rosada' conduzida em espaldeira (esp) a céu aberto e em "Y" sob telado plástico (Y telado) e em ambiente externo (ext), em dia nublado $(a, b, c)$ e ensolarado $(d, e, f)$. 
TABELA 1 - Valores médios da temperatura máxima e mínima, umidade relativa e radiação solar obtidos em vinhedos de 'Niagara Rosada' conduzidos em espaldeira a céu aberto e em Y sob telado plástico, em Louveira (SP).

\begin{tabular}{lcc}
\hline Variável & $\begin{array}{c}\text { Espaldeira a } \\
\text { céu aberto }\end{array}$ & Y sob telado plástico \\
\hline Temperatura máxima $\left({ }^{\circ} \mathrm{C}\right)$ & $25,8 \mathrm{a}$ & $25,9 \mathrm{a}$ \\
Temperatura mínima $\left({ }^{\circ} \mathrm{C}\right)$ & $16,0 \mathrm{a}$ & $15,9 \mathrm{a}$ \\
Umidade relativa $(\%)$ & $82,0 \mathrm{a}$ & $83,9 \mathrm{a}$ \\
Radiação solar ao nível do cacho $\left(\mathrm{MJ} \cdot \mathrm{m}^{-2} \cdot \mathrm{dia}^{-1}\right)$ & $3,4 \mathrm{a}$ & $6,7 \mathrm{~b}$ \\
Transmissividade ao nível do cacho $(\%)$ & $20,9 \mathrm{a}$ & $41,1 \mathrm{~b}$ \\
Transmissividade do telado $(\%)$ & - & 79,6 \\
\hline
\end{tabular}

Médias seguidas de mesma letra na horizontal não diferem entre si, pelo teste t a 5\%.

TABELA 2 - Valores médios de produção, massa dos cachos, número de cachos, comprimento e largura dos cachos e das bagas em vinhedo de 'Niagara Rosada' conduzido em espaldeira a céu aberto e em Y sob telado plástico, em Louveira (SP), durante a safra de verão.

\begin{tabular}{lcccc}
\hline Variável & $\begin{array}{c}\text { Espaldeira } \\
\text { céu aberto }\end{array}$ & $\begin{array}{c}\text { Y sob telado } \\
\text { plástico }\end{array}$ & $\begin{array}{c}\text { Espaldeira } \\
\text { céu aberto }\end{array}$ & $\begin{array}{c}\text { Y sob telado } \\
\text { plástico }\end{array}$ \\
\hline & & $\mathbf{2 0 0 8}$ & & \multicolumn{2}{c}{$\mathbf{2 0 0 9}$} \\
Produção $\left(\mathrm{kg} . p l a n t a^{-1}\right)$ & $3,21 \mathrm{a}$ & $13,18 \mathrm{~b}$ & $3,09 \mathrm{a}$ & $15,01 \mathrm{~b}$ \\
Produtividade $\left({\left.\mathrm{t} . h \mathrm{~h}^{-1}\right)}^{2}\right.$ & $26,78 \mathrm{a}$ & $29,43 \mathrm{~b}$ & $25,68 \mathrm{a}$ & $33,49 \mathrm{~b}$ \\
Número cachos por planta & $12,0 \mathrm{a}$ & $43,8 \mathrm{~b}$ & $12,4 \mathrm{a}$ & $52,9 \mathrm{~b}$ \\
Massa dos cachos $(\mathrm{g})$ & $268,2 \mathrm{a}$ & $301,1 \mathrm{~b}$ & $248,9 \mathrm{a}$ & $283,9 \mathrm{~b}$ \\
Comprimento do cacho $(\mathrm{cm})$ & $12,9 \mathrm{a}$ & $14,5 \mathrm{~b}$ & $12,8 \mathrm{a}$ & $14,2 \mathrm{~b}$ \\
Largura do cacho $(\mathrm{cm})$ & $7,7 \mathrm{a}$ & $9,8 \mathrm{~b}$ & $7,8 \mathrm{a}$ & $8,7 \mathrm{~b}$ \\
\hline
\end{tabular}

Médias seguidas de mesma letra na horizontal não diferem entre si, pelo teste t, a 5\% dentro do mesmo ano agrícola.

\section{CONCLUSÕES}

A comparação dos sistemas de condução da 'Niagara Rosada' em Y sob telado plástico e em espaldeira permitiu verificar que:

1. Não ocorreu diferença nos valores diários de temperatura do ar máxima e mínima, e umidade relativa do ar medidas ao nível do cacho;

2. Transmissão de radiação solar ao nível dos cachos no sistema em Y sob telado plástico (41\%) foi superior ao espaldeira (21\%);

3. A produtividade e o tamanho dos cachos foram superiores no sistema de condução em Y sob telado plástico.

\section{REFERENCIAS}

CARDOSO, L S.; BERGAMASCHI, H.; COMIRAN, F.; CHAVARRIA, G.; MARODIN, G.A.B.; DALMAGO, G.A.; SANTOS, H. P.; MANDELLI, F. Alterações micrometeorológicas em vinhedos pelo uso de coberturas de plástico. Pesquisa Agropecuária Brasileira, Brasília, v.43, n.4, p.441-447, 2008.
CHAVARRIA, G.; SANTOS, H. P.; SÔNEGO, O.R.; MARODIN, G.A.B.; BERGAMASCHI, H.; CARDOSO, L.S. Incidência de doenças e necessidade de controle em cultivo protegido de videira. Revista Brasileira de Fruticultura, Jaboticabal, v.29, n.3, p.477-482, 2007.

CHAVARRIA, G.; CARDOSO, L.S.; BERGAMASCHI, H.; SANTOS, H.P.; MANDELLI, F.; MARODIN, G.A.B. Microclima de vinhedos sob cultivo protegido. Ciência Rural, Santa Maria, v.39, n.7, p.2029-2034, 2009.

CONCEIÇÃO, M.A.; MARIN, F.R. Condições microclimáticas em um parreiral irrigado coberto com tela plástica. Revista Brasileira de Fruticultura, Jaboticabal, v.31, n.2, p.423-431, 2009.

CONTE, A. Comportamento da videira Niágara Rosada submetida à poda de verão, sob estufa plástica, em Bento Gonçalves. 1996. 71 f. Dissertação (Mestrado) - Universidade Federal do Rio Grande do Sul, Porto Alegre, 1996. 
DETONI, A.M.; CLEMENTE, E.; FORNARI, C. Produtividade e qualidade da uva 'Carbenet Sauvignon' produzida sob cobertura de plástico em cultivo orgânico. Revista Brasileira de Fruticultura, Jaboticabal, v.29, n.3, o.530-534, 2007.

EPAGRI. Sistema de sustentação da videira na forma de "Ypsilon" ou manjedoura com cobertura plástica. Santa Catarina: Empresa de Pesquisa Agropecuária e Extensão Rural. 2006. 2p. Fôlder.

FERREIRA, M.A.; PEDRO JÚNIOR, M.J.; SANTOS, A.O.; HERNANDES, J.L. Modificação parcial do ambiente de cultivo da videira 'Cabernet Sauvignon' sobre diferentes porta-enxertos: efeito sobre a produção e teor de sólidos solúveis, Bragantia, Campinas, v.63, n.3, p.439-145, 2004.

GONÇALVES, A.L. Efeito do sombreamento artificial contínuo no microclima, crescimento e produção da videira 'Niagara Rosada'. 2007. 62 f. Dissertação (Mestrado) - Instituto Agronômico, Campinas, 2007.

LULU, J.; PEDRO JÚNIOR, M. J. Microclima de vinhedos cultivados sob cobertura plástica e a céu aberto. Revista Brasileira de Agrometeorologia, Santa Maria, v. 14, n.1, p.106-115, 2006.

MOTA, C.S.; AMARANTE, C.V.T.; SANTOS, H.P.; ZANARDI, O.Z. Comportamento vegetativo e produtivo de videiras 'Cabernet Sauvignon' cultivadas sob cobertura plástica. Revista Brasileira de Fruticultura, Jaboticabal, v. 30, n.1, p.148-153, 2008.
PEDRO JÚNIOR, M.J.; PEZZOPANE, J.R.; HERNANDES, J.L.; ABRAMIDES, P.L.G. Sistemas de condução da videira 'Niagara Rosada': efeitos na transmissão de radiação solar e na produtividade. Revista Brasileira de Agrometeorologia, Piracicaba, v.14, n.1, p.1-9. 2006.

PEDRO JÚNIOR, M.J.; HERNANDES, J.L.; ROLIM, G.S. Sistema de condução em Y com e sem cobertura plástica: microclima, produção, qualidade do cacho e ocorrência de doenças fúngicas na videira 'Niagara Rosada'. Bragantia, Campinas, v.70, n.1, p.228-233. 2011.

PERUZZO, E.L. Efeitos do sombreamento e da área foliar na produção e qualidade do fruto de Vitis labrusca L. cv. 'Niagara Rosada'. 1990. 69 f. Dissertação (Mestrado) - Universidade Federal de Viçosa, Viçosa, 1990.

SCHIEDECK, G.; MIELE, A.; BARRADAS, C.I.N.; MANDELLI, F. Maturação da uva Niagara Rosada cultivada em estufa de plástico e a céu aberto. Ciência Rural, Santa Maria, v.29, n.4, p.629-633. 1999.

SCHUCK, E.; CALIARI, V.; ROSIER, J.P. Uso da plasticultura na melhoria da qualidade de frutas. In: ENFRUTE, 7., 2004, Friburgo. Anais... 8p. 